\title{
Celiac plexus neurolysis for the treatment of upper abdominal cancer pain
}

This article was published in the following Dove Press journal:

Neuropsychiatric Disease and Treatment

16 August 2013

Number of times this article has been viewed

Manoel Jacobsen Teixeira

Eloy Rusafa Neto

José Cláudio Marinho da

Nóbrega

Jairo Silva dos Ângelos

Miguel San Martin

Bernardo Assumpção de

Monaco

Erich Talamoni Fonoff

Department of Neurology, Division of Functional Neurosurgery of the Institute of Psychiatry, University of São Paulo School of Medicine, São Paulo, Brazil
Correspondence: Erich Talamoni Fonoff Division of Functional Neurosurgery, Department of Neurology, University of São Paulo School of Medicine,

Ovídeo Pires de Campos 785, São Paulo, 0I23 I-000, Brazil

Tel +55II 266। 6608

Emailfonoffet@usp.br
Abstract: Optimal treatment of oncologic pain is a challenge to all professionals who deal with cancer and its complications. The management of upper abdominal pain is usually difficult and it is often refractory to conservative therapies. In this context, celiac plexus neurolysis (CPN) appears to be an important and indispensable tool because it alleviates pain, gives comfort to patients and is a safe procedure. In this study, the importance of CPN is reviewed by a retrospective study of 74 patients with pain due to upper abdominal cancer. Almost all cases evaluated (94.6\%) had an excellent result after CPN and the majority of side effects were transitory.

Keywords: pain, celiac plexus, alcohol neurolysis, cancer

\section{Introduction}

Injections of neurolytic agents to destroy nerves and interrupt pain pathways have been used for several years. ${ }^{1-3}$ Celiac plexus neurolysis (CPN) is an ablative procedure of the celiac plexus (CP) that aims to destroy afferent pain transmitting fibers from abdominal viscera. It can be chemical, thermic or surgical, with the chemical method being limited to alcohol or phenol.

$\mathrm{CPN}$ is thought to be a safe and effective technique, indicated in patients with severe and intractable pain, in whom less aggressive maneuvers are ineffective or intolerable because of either poor physical condition or development of side effects. ${ }^{4}$ The World Health Organization Cancer Pain Relief Program recommends CPN for pain relief in patients with upper abdominal cancer. ${ }^{3-6}$

The noteworthy adverse effects of alcohol neurolysis include regional pain, hypotension, diarrhea, hypoxemia, and acute alcoholic intoxication, ${ }^{7,8}$ most of them transient and controllable.

The CP is situated retroperitoneal in the upper abdomen at the level of the 12 th thoracic and 1 st lumbar vertebrae, anterior to the crura of the diaphragm. It surrounds the abdominal aorta, celiac and superior mesenteric arteries. The plexus is comprised of a network of nerve fibers, from both sympathetic and parasympathetic systems. It receives parasympathetic fibers from the vagus nerve and contains two large ganglia that receive sympathetic fibers from the three splanchnic nerves; the right ganglion is, on average, $0.6 \mathrm{~cm}$ inferior to the celiac artery, whereas the left is $0.9 \mathrm{~cm}$ inferior.

The neural information related to visceral pain is not carried on by sympathetic nerve fibers and these pain syndromes are not dependent on sympathetic activity within the CP. The afferent fibers that bring up visceral sensory information from the upper abdomen, including the pancreas, diaphragm, liver, spleen, stomach, 
bowel, proximal portion of the transverse and ascending colon, suprarenal glands, kidneys, abdominal aorta and mesentery are located within the plexus anatomical region. ${ }^{4,9}$ Impulses pass from the $\mathrm{CP}$ to the splanchnic nerves and enter the spinal cord from the 5 th to the 9 th thoracic segments. ${ }^{10}$

Pain due to oncologic infiltration of somatic territories into the abdominal wall is not conducted through celiac plexus fibers and, therefore, cannot be treated by $\mathrm{CP}$ ablation.

\section{Objective}

This study aims to evaluate the importance of alcohol CPN in the treatment of visceral pain due to upper abdominal cancer.

\section{Material and methods}

We retrospectively reviewed 74 patients with upper abdominal cancer and visceral pain syndromes who were submitted to percutaneous alcohol CPN from June 1989 to March 2011. Patients were selected to the procedure while having disabling pain, refractory to optimized medication and to other nonsurgical procedures; all of them had advanced oncologic disease with life expectancy close to one year.

Celiac plexus neurolysis was first described by Ischia et al in $1919 ;{ }^{11}$ since then, several modifications have been proposed. Our practice was based on the description of percutaneous splanchnic nerve block technique: a patient under general anesthesia is positioned in the prone position and the skin is cleaned with antiseptics. Then percutaneous fluoroscopic guided bilateral puncture is performed with a needle, 7 centimeters lateral to the midline, 45 degrees in the coronal plane, and 15 degrees cephalic to the lateral portion of the L1 vertebral body. The tip of the needle is placed under lateral-lateral and antero-posterior fluoroscopic guide, 1 to 2 centimeters anterior to the L1 vertebral body. Aspiration is first performed to ensure that vascular puncture has not occurred, then $3 \mathrm{~mL}$ to $5 \mathrm{~mL}$ of contrast agent is injected to visualize by fluoroscopy the contrast diffusion to the retrocrural and retroaortic space, anterior and lateral to the superior lumbar and inferior thoracic vertebra. The injection of $20 \mathrm{~mL}$ to $50 \mathrm{~mL}$ of absolute alcohol under fluoroscopy finalizes the procedure (Figure 1).

Response to treatment was evaluated up to 10 days after the procedure. Response was considered "bad" when pain persisted with no improvement, "good" when partial relief was achieved with improvement of quality of life, and "excellent" when pain was completely abolished.

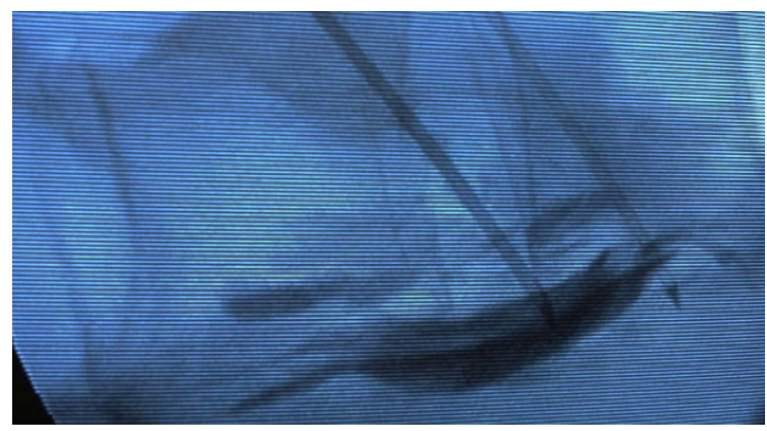

Figure I Fluoroscopic view of the spine in lateral position at the level of $L I$ with the insertion tubes in each side of the prevertebral space. Note: This is the intended target for this procedure.

\section{Results}

Patients were aged between 25 and 81 years old, with a mean age of 56.8 years. Thirty-nine of the 74 patients were male $(52.7 \%)$, and thirty-five were female (47.3\%). Seventy patients $(94.6 \%)$ submitted to percutaneous alcohol CPN had an excellent response to treatment and four of them $(5.4 \%)$ had a good response. The patients who had an excellent response to CPN did not need opioid medication and only stayed on lower doses of this medication for a few days in order to rule out the possibility of opioid withdrawal syndrome. The group of patients who had a good response to the CPN procedure still required some opioid and/or anti-inflammatory medication, but the analgesic medication became effective in controlling pain.

The majority of patients who underwent the procedure had uncontrolled disease and most of them experienced a progression of the disease afterwards. The CPN procedure aimed to improve the quality of life by reducing pain, and did not interfere with the disease process itself. Patients in this treatment group had a poor prognosis and low survival rate at the time of initiating the procedure. Theoretically, patients who experienced an improvement in their quality of life should respond better to treatment of their primary disease, but this fact was not really observed in this investigation.

Complications related to the procedure were: transient pain in the puncture location in 42 patients $(56.7 \%)$, transitory diarrhea in 26 patients $(35.1 \%)$, and hypotension responsive to volume infusion in 19 patients $(25.6 \%)$, see Figure 2. No significant pleural effusion occurred in this study. One patient experienced permanent crural paraplegia $(1.35 \%)$; this was the only severe complication in this trial. This patient was a 65-year-old with typical upper abdominal pain related to advanced pancreatic cancer. Around six months before 


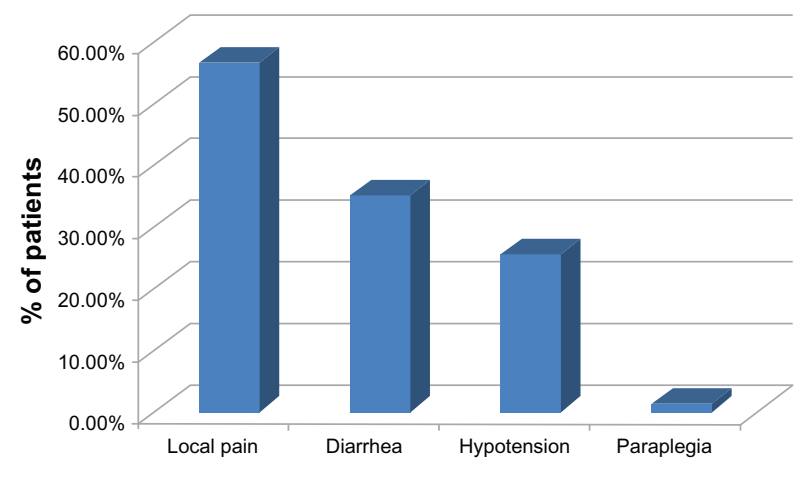

Figure 2 Different adverse effects related to alcohol celiac plexus neurolysis.

the procedure the patient underwent local radiotherapy in order to control the cancer, using the same volume of alcohol that was used in the CPN procedure guided by fluoroscopy. The neurological examination revealed anterior spinal artery syndrome with severe neurological motor deficits, with no significant sensory loss in the same territory.

\section{Discussion}

The control of visceral pain related to abdominal cancer, especially in the upper abdomen remains a challenge. Pain control is one of the most important aspects of quality of life maintenance during the treatment of these cancer patients, who often are in an advanced stage of the disease, with a short life expectancy. ${ }^{2,10}$ Unfortunately, many patients have resistance to pain medication and side effects of opioids. ${ }^{1-3,4}$

The celiac plexus has a diffuse anatomical structure and is composed of more than two ganglia, therefore regardless of the technique used, CPN may have a long-lasting benefit in $70 \%$ to $90 \%$ of patients with upper abdominal cancer, appearing as a safe and cost-effective approach to treating visceral pain associated with cancer. ${ }^{12,13}$

Despite the World Health Organization Cancer Pain Relief Program recommending CPN as the most suitable intervention in a palliative setting, this procedure still carries some misconceptions by many physicians, withholding a potential improvement in the quality of life of many terminally ill patients. ${ }^{14}$

Chemical ablative procedures of a nerve or a nerve group are preferred to other mechanical modalities in order to disrupt diffuse neural networks, such as the celiac plexus. Alcohol is preferred to phenol because of the perception that it leads to more complete ablation and avoids the potential mutagenic effects of phenol. ${ }^{15}$
Lillemoe et $\mathrm{al}^{2}$ concluded that $\mathrm{CP}$ alcohol neurolysis for irreversible abdominal pain from pancreatic cancer can provide significant analgesia for up to 6 months and improve survival $(P<0.0001)$. Wong et al, ${ }^{10}$ in a prospective randomized trial proved this pain relief to be more effective than optimized analgesic therapy alone, however with no impact on life quality or survival.

Studies comparing percutaneous CPN with the use of opioids suggest that $\mathrm{CPN}$ results in a mild-to-moderate sustained reduction of pain in pancreatic cancer and an important decrease in opioid use, but does not eliminate the need for additional medication. ${ }^{3,4,16,17}$ Our study could also reproduce the good results found in the literature since all patients involved exhibited satisfactory control of pain.

Besides the fluoroscopic guided percutaneous celiac neurolysis, the computed tomography (CT) guided procedure can also be mentioned, also the intraoperative approach and the endoscopic ultrasound guided procedure (EUS). Yamamuro et $\mathrm{al}^{14}$ state that there are no significant differences in efficacy between fluoroscopic and CT guided CPN, although the use of CT assures a correct needle tip placement.

Currently, there are few data about CPN under EUS guidance. However, the results are comparable to other conventional methods used to relieve pancreatic pain with neurolytic agent injections. . $^{12,19,20}$

The transient adverse effects after alcohol CPN in this study were the same observed in correlated articles. ${ }^{7,10,14,21}$ Our one case of a severe complication $(1.35 \%$, crural paraplegia) was an unexpected event, nevertheless it is under the rate of $2 \%$ reported in the literature for neurological deficits after CPN..$^{14,21}$ A possible hypothesis was the involvement of the Artery of Adamkiewicz either as a direct lesion or a severe arterial spasm responsible for an ischemic event in the spinal cord. This artery is the largest anastomotic segmental artery in the lumbar region responsible for the blood supply to the anterior portions of the terminal spinal cord. In $75 \%$ of people, the artery of Adamkiewicz originates on the left side of the aorta between the T8 and L1 vertebral segments. ${ }^{22}$ Although, this a relatively rare event, similar cases were reported after each of the techniques: the posterior percutaneous under image guidance, ${ }^{22,24}$ the anterior open technique under direct view ${ }^{25,26,27}$ and the anterior endoscopic guided technique. ${ }^{28}$

The benefits of CPN are very well known qualitatively, however quantitative studies are needed. Pain practitioners should consider the role of these blocks in adjuvant therapy for the optimal treatment of cancer pain. 


\section{Conclusion}

Upper abdominal cancer causes severe pain in most patients and is often difficult to treat. Palliation of pain in these cases often requires a multidisciplinary approach, with options including oral analgesics, chemotherapy, radiotherapy, psychotherapy, nonsurgical procedures and CPN.

Timely interventional cancer pain therapies complement conventional pain management by reducing the need for highdose opioid therapy and its associated toxicity.

In a seriously impaired cancer patient scenario CPN appears as an effective procedure because it relieves visceral pain, generally with no serious adverse effects and excellent results. This positive impact on quality of life after CPN is a central aspect of this procedure among other palliative care therapeutic options.

\section{Disclosure}

The authors report no conflicts of interest in this work.

\section{References}

1. Brown DL, Moore DC. The use of neurolytic plexus block for pancreatic cancer: anatomy and technique. J Pain Symptom Manage. 1988;3: 206-209.

2. Lillemoe KD, Cameron JL, Kaufman HS, et al. Chemical splancnicectomy in patients with unresectable pancreatic cancer. A prospective randomized trial. Ann Surg. 1993;217:447-457.

3. Kawamata M, Ishitani K, Ishikawa K, et al. Comparison between celiac plexus block and morphine treatment on quality of life in patients with pancreatic cancer pain. Pain. 1996;64:597-602.

4. Polati E, Finco G, Gottin L, et al. Prospective randomized double-blind trial of neurolytic celiac plexus block in patients with pancreatic cancer. Br J Surg. 1998;85:199-201.

5. Lankisch PG. Natural course of chronic pancreatitis. Pancreatology. 2001;1:3-14.

6. Caraceni A, Portenoy RK. Pain management in patients with pancreatic carcinoma. Cancer. 1996;78:639-653.

7. Davies DD. Incidence of major complications of neurolytic coeliac plexus block. J R Soc Med. 1993;86:264-266.

8. Moore JC, Adler DG. Celiac plexus neurolysis for pain relief in pancreatic cancer. J Support Oncol. 2009;7(3):88-90.

9. Plancarte R, Velasquez R, Patt R. Neurolytic blocks of the sympathetic axis. In: Pratt RB, editor. Pain. Philadelphia: Lippincott Williams \& Wilkins; 1993:377.
10. Wong GY, Schroeder DR, Carns PE, et al. Effect of neurolytic celiac plexus block on pain relief, quality of life, and survival in patients with unresectable pancreatic cancer: a randomized controlled trial. JAMA. 2004;291:1092-1099.

11. Ischia S, Polati E, Finco G, Gottin L. Celiac block for the treatment of pancreatic pain. Curr Rev Pain. 2000;4(2):127-133.

12. Levy MJ, Topazian MD, Wiersema MJ, et al. Initial evaluation of the efficacy and safety of endoscopic ultrasound-guided direct ganglia neurolysis and block. Am J Gastroenterol. 2008;103(1):98-103.

13. Gress F, Schmitt C, Sherman S, et al. A prospective randomized comparison of endoscopic ultrasound and computed tomographyguided celiac plexus block for managing chronic pancreatitis pain. Am J Gastroenterol. 1999;94:900-905.

14. Yamamuro M, Kusaka K, Kato M, Takahashi M. Celiac plexus block in cancer pain management. Tohoku J Exp Med. 2000;192(1):1-18.

15. Wang YC, Lee WH, Chen WY, Fu YM. Histopathological examination of chemo-sympathectomy in cats. Neurol Res. 2000;22(4):420-424.

16. Mercadante $\mathrm{S}$. Celiac plexus block versus analgesics in pancreatic cancer pain. Pain. 1993;52:187-192.

17. Yan BM, Myers RP. Neurolitic celiac plexus block for pain control in unresectable pancreatic cancer. AM J Gastroenterol. 2007;102: 430-438.

18. Iwata K, Yasuda I, Enya M, et al. Predictive factors for pain relief after ultrasound-guided celiac plexus neurolysis. Dig Endosc. 2011;23(2): 140-145.

19. Wiersema MU, Wiersema LM. Endosonography-guided celiac plexus neurolysis. Gastrointest Endosc. 1996;44:656-662.

20. Sakamoto H, Kitano M, Komaki T, et al. Endoscopic ultrasound-guided neurolysis in pancreatic câncer. Pancreatology. 2011;11(Suppl 2): S52-S58.

21. Eisenberg E, Carr DB, Chamlers TC. Neurolytic celiac plexus block for treatment of cancer pain: a meta-analysis. Anesth Analg. 1995;80(2): 290-295.

22. Lazorthes G, Gouaze A, Zadeh JO, et al. Arterial vascularization of the spinal cord. Recent studies of the anastomotic substitution pathways. J Neurosurg. 1971;35(3):253-262.

23. Takeda J, Namai H, Fukushima K. Anterior spinal artery syndrome after left celiac plexus block. Anesth Analg. 1996;83(1):178-179.

24. Hayakawa J, Kobayashi O, Murayama H. Paraplegia after intraoperative celiac plexus block. Anesth Analg. 1997;84(2):447-448.

25. Kinoshita H, Denda S, Shimoji K, Ohtake M, Shirai Y. Paraplegia following coeliac plexus block by anterior approach under direct vision. Masui. 1996;45(10):1244-1246.

26. Abdalla EK, Schell SR. Paraplegia following intraoperative celiac plexus injection. J Gastrointest Surg. 1999;3(6):668-671.

27. Kumar A, Tripathi SS, Dhar D, Bhattacharya A. A case of reversible paraparesis following celiac plexus block. Reg Anesth Pain Med. 2001; 26(1):75-78.

28. Fujii L, Clain JE, Morris JM, Levy MJ. Anterior spinal cord infarction with permanent paralysis following endoscopic ultrasound celiac plexus neurolysis. Endoscopy. 2012;44:E265-E266.
Neuropsychiatric Disease and Treatment

\section{Publish your work in this journal}

Neuropsychiatric Disease and Treatment is an international, peerreviewed journal of clinical therapeutics and pharmacology focusing on concise rapid reporting of clinical or pre-clinical studies on a range of neuropsychiatric and neurological disorders. This journal is indexed on PubMed Central, the 'PsycINFO' database and CAS.

\section{Dovepress}

The manuscript management system is completely online and includes a very quick and fair peer-review system, which is all easy to use. Visit http://www.dovepress.com/testimonials.php to read real quotes from published authors. 